\title{
Sozinho, me ajoelho; Juntos, nos levantamos: gesto e performance em levantes
}

\author{
Reno Beserra Almeida' \\ https://orcid.org/0000-0002-1784-8484 \\ I - Universidade Federal de Pernambuco. \\ Recife (PE). Brasil.
}

Resumo: Neste ensaio, abordamos o racismo, a violência policial e os recentes protestos políticos nos Estados Unidos amparados metodologicamente pelo campo de estudos da performance, ou seja, pensando esses acontecimentos como eventos performáticos. Sob essa chave, analisamos o assassinato de George Floyd e os protestos que emergiram em resposta à sua morte, pensados aqui a partir do conceito de levante, e um gesto que com notável frequência era repetido por diversos manifestantes: o de se ajoelhar. O gesto, nesse caso, é o momento intensamente performático no qual um corpo se expõe e cria a si mesmo e um outro espaço sensível possível, mesmo que efêmero, e que liga cada manifestante a toda uma linhagem de ativistas que lutaram e ainda lutam pelo fim da repetição do roteiro macabro da violência racial.

Palavras-chave: racismo; performance; gesto; violência racial; comunicação e política; levantes.

Abstract: Alone, I kneel; Together, we stand up: gesture and performance
in uprisings - In this essay we address racism, police violence and the recent
political protests in the United States methodologically supported by the field
of performance studies, that is, thinking of them as performatic events. Under
this key, we analyze the murder of George Floyd and the protests that emer-
ged in response to his death, thought here through the concept of uprising,
and the gesture that with remarkable frequency was repeated by several
demonstrators: the kneeling. The gesture, in this case, is the intensely perfor-
matic moment where a body exposes and creates itself and another possible
sensible space, even if ephemeral, and which links each protester to a whole 
lineage of activists who fought and are still fighting for the end of the replay of the macabre script of racial violence.

Keywords: racism; performance; gesture; racial violence; communication and politics; uprisings.

\section{Introdução}

Um conjunto de imagens ganhou o mundo e as telas de televisões, computadores e celulares no ano de 2020, logo após a morte do afroamericano George Floyd, sufocado por uma força policial que deveria preservar sua vida, não miná-la. Por um lado, imagens de violência nas quais vemos, por diferentes ângulos, o policial Derek Chauvin subjugar com crueldade Floyd, impondo-o a um martírio que por fim o levou à morte. Por outro lado, imagens de protestos - ou levantes - de sujeitos que já não mais aguentam a repetição de um ciclo de violência racial que atravessa a própria formação dos Estados Unidos como nação; imagens atravessadas pela emergência de um gesto: o de se ajoelhar.

Propomos, neste ensaio, abordar esses diferentes registros imagéticos sob a luz dos estudos de performance, encarando tanto a violência policial racista quanto os protestos que emergem em resposta como expressões de comportamento restaurado (SCHECHNER, 2003, p. 27), ou seja, eventos marcados por constantes reativações e reencenações (TAYLOR, 2013). Neste movimento, interessa-nos o gesto que vem à tona nas imagens. O gesto, pensado com base em Giorgio Agamben (2018, p. 2), é chave conceitual para uma aproximação dessas imagens com outras, ligadas à luta antirracista e por direitos civis, em uma montagem na qual nos atrai menos os aspectos formais do que uma aproximação por meio da gestualidade. O gesto é o momento em que o corpo, ou o conjunto de corpos, expressa-se como algo novo, torna-se imagem. Simultaneamente, é o que permite que utilizemos uma imagem para falar de outra e que encaremos esses registros imagéticos como objetos presentes na memória coletiva e daí tirados para dar forma aos desejos e às novas lutas por emancipação (DIDI-HUBERMAN, 2016, p. 18).

\section{"Não consigo respirar"}

Na noite de 25 de maio de 2020, dois oficiais da polícia de Minneapolis, capital de Minnesota, estado ao norte dos Estados Unidos, encaminharam-se 
à esquina entre a East 38th Street e Chicago Avenue, respondendo ao chamado do caixa da loja de conveniência Cup Foods. O funcionário alegou que um sujeito "terrivelmente bêbado" pagara um maço de cigarros com uma nota de 20 dólares supostamente falsa e, quando confrontado pelo funcionário, que pediu que o maço fosse devolvido, o sujeito se recusou. O protocolo seguido pelos trabalhadores da loja recomenda que a autoridade policial seja chamada em casos como o que havia ocorrido. Às 20:08, J. Alexander Kueng e Thomas Lane chegaram ao local e abordaram George Floyd, homem negro de 46 anos que havia passado a nota alegadamente falsa.

Câmeras de estabelecimentos comerciais naquela esquina e de uma pessoa sentada em um carro estacionado atrás da SUV de Floyd registraram em imagens o tratamento dedicado pelos policiais ao homem negro, uma reencenação do trato violento dado a cidadãos afroamericanos por forças de segurança. Floyd, que se recusara a sair do banco do motorista de seu carro, foi retirado à força e algemado por Thomas Lane, que logo a seguir requisitou reforço policial para lidar com um indivíduo "fora de controle e agindo violentamente", descrição refutada pelas imagens capturadas nas diferentes câmeras, arquivos imagéticos que são tanto provas diretas quanto um registro macabro do acontecimento e que permitem ver um homem algemado que age de forma acuada e aterrorizada.

Às 20:17, com Floyd já sentado no banco traseiro de uma viatura policial, os policiais Derek Chauvin e Tou Thao se juntaram a Lane e Kueng. Chauvin retirou Floyd violentamente da viatura sem motivo plausível e, em seguida, se ajoelhou sobre seu pescoço. As violentas imagens dos momentos seguintes, registradas sob diversos ângulos, são algumas das cenas mais marcantes e profusamente compartilhadas do ano de 2020. Chauvin, empertigado em seu uniforme policial, tem o olhar sádico de um justiceiro enquanto sufoca Floyd, que, em completo desespero, apenas consegue gritar "não consigo respirar" e chamar por sua mãe (FIG. 1). O policial manteve seu joelho sobre o pescoço de Floyd por 9 minutos e 30 segundos, ainda que Floyd já jazesse inconsciente há algum tempo sob o peso de Chauvin. No horário de 21:25, George Floyd foi declarado morto na sala de emergência do Centro Médico Hennepin County.

Diferentes veículos de comunicação, como New Yorker ${ }^{1}$ e The Atlantic² des- $^{-}$ tacaram o fato de que as imagens da morte de George Floyd eram como

\footnotetext{
1 Matéria disponível no link: <https://www.newyorker.com/news/daily-comment/the-death-ofgeorge-floyd-in-context >. Acesso em: 6 de abr. de 2021.

2 Matéria disponível no link: <https://www.theatlantic.com/politics/archive/2020/06/wesley-lowery-george-floyd-minneapolis-black-lives/612391/>. Acesso em: 6 de abr. de 2021.
} 
um déjà vu, profundamente chocante, mas não surpreendente. As últimas palavras de Floyd ("não consigo respirar"), um verdadeiro testamento, o ligavam diretamente a Eric Garner, afroamericano de 43 anos morto sufocado em 2014, que repetiu a mesma frase enquanto o policial Daniel Pantaleo Ihe aplicava um mata leão. Um evento traumático, conforme sustenta Diana Taylor (2009, p. 8), é como uma performance de longa duração, caracterizada "pela natureza das suas repetições". Pensando a violência policial em sua ligação com o racismo sob a luz dos estudos de performance, é possível analisar esses eventos como comportamentos restaurados, acontecimentos que ocorrem "nunca pela primeira vez" (SCHECHNER, 2003, p. 35). A morte de Floyd, vista sob essa ótica, invoca diretamente o assassinato de diversos outros afroamericanos, como Trayvon Martin, Breonna Taylor e Garner, mortos por membros de forças policiais ou paramilitares. Acontecimentos que se dão nunca pela primeira vez. Luta-se, então, para que sejam pela última.

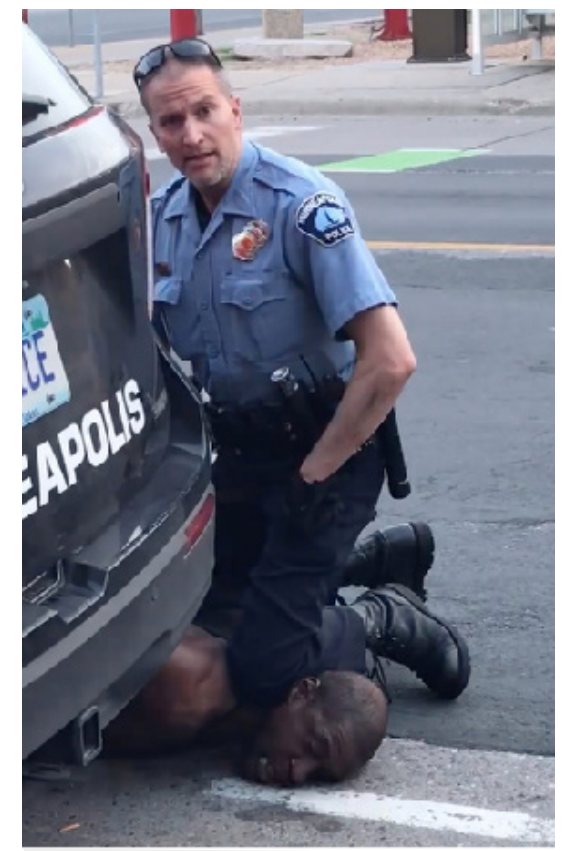

Figura 1. Policial Derek Chauvin ajoelhado sobre o pescoço de George Floyd. Fonte:The Sun ${ }^{1}$ 


\section{Um roteiro trágico e personagens sem rosto}

Em uma matéria que aponta a morte de George Floyd como um "ponto de ruptura" na luta contra a violência racista policial, ligando diretamente o caso com diversos outros assassinatos recentes de indivíduos negros nos Estados Unidos, o jornal americano The Atlantic destaca como Miki Noor, ativista afroamericana, ao se juntar ao Movement for Black Lives ${ }^{4}$, logo se familiarizou com um ciclo tétrico e aparentemente sem fim: polícia assassina alguém; ativistas protestam; pequenas reformas nos sistemas judicial e policial são conquistadas; polícia assassina mais alguém...

As semelhanças entre os assassinatos de afroamericanos, independentemente de seu gênero, não é apenas coincidência. Seguem, com assustadora frequência, um roteiro. Como sustenta Diana Taylor (2013, p. 66), um roteiro não é necessariamente mimético, funcionando não por meio da duplicação, mas da reativação. O roteiro "ressuscita e reativa velhos dramas" (ibidem, p. 60), em uma espécie de espectrologia que assombra o presente. Os atores e os papéis desempenhados no roteiro da violência racial se reiteram com diferenças pontuais: a vítima negra é considerada virtual ou atualmente um indivíduo agressivo, fora de controle, cujo risco que representa justifica uma intervenção truculenta; o agressor é o sujeito que, por meio da força, conseguirá domar a vítima fora de controle, mesmo que seja com a morte desta; a justiça que julga o violentador, reproduzindo uma estrutura social racista, o absolve; ou, se o condena, permanece inalterado todo um cenário que permite que a violência racial se reproduza.

Como aponta Silvio Almeida (2019, p. 111), os Estados Unidos — assim como Brasil ou África do Sul —, "não são o que são apesar do racismo, mas são o que são graças ao racismo", que é estrutural na e da sociedade americana, afetando a "sua configuração interna, estipulando padrões hierárquicos, naturalizando formas históricas de dominação e justificando a intervenção estatal sobre grupos sociais discriminados" (ibidem, p. 109). O racismo é o fenômeno que define o quadro mais amplo no qual o roteiro e os papéis acima referidos são materializados.

O racismo, como situa Achille Mbembe (2018, p. 70), é uma operação do imaginário por meio da qual o racista - e, podemos afirmar, a sociedade racista - entra em contato com as regiões mais sombrias do inconsciente. 
O rosto do sujeito negro é ocultado, relegado ao segundo plano, e em sua substituição emerge das:

[...] profundezas da imaginação um rosto de fantasia, um simulacro de rosto e uma silhueta que, desse modo, tomam o lugar de um corpo e um rosto humanos. O racismo consiste, pois, em substituir aquilo que é por algo diferente, uma realidade diferente (MBEMBE, 2018, p. 69).

O racismo - e a violência racial - depende dessa constante substituição, uma projeção branca de informações indesejáveis em uma existência tornada outra, um simples objeto (KILOMBA, 2019, p. 117). Em seu pedido de reforço, Thomas Lane descreveu Floyd como um indivíduo fora de controle, estado totalmente refutado pela gravação das câmeras de segurança. A imagem do homem ou da mulher negra violenta e descontrolada é um estereótipo que surge como um simulacro de rosto que toma o lugar da face original (MBEMBE, 2018, p. 69), um signo "ex-ótico" (MARTINS, 2003, p. 64), sempre situado fora do campo da compreensão. O estereótipo é uma força determinante na reativação do roteiro da violência racista, uma vez que funciona como uma forma de representação posta no lugar da realidade (HOOKS, 2019, p. 303), que permite justamente que o indivíduo negro não tenha um rosto, apenas uma existência objetificada. Nessa perspectiva, qualquer violência passa a ser, então, justificada para conter a pulsão destruidora do vivente sem face.

Pensando o racismo como um evento performático marcado por um roteiro que influencia e mesmo determina papéis, ações e ocupações na experiência sensível, é pertinente observar que o "arcabouço portátil" (TAYLOR, 2013, p. 60) do roteiro performático permite oclusões, dando proeminência a certas visões, a certos regimes de verdade (FOUCAULT, 1979, p. 12), em detrimento de outros que são tirados de vista. Podemos interpretar nesse sentido a afirmação de bell hooks (2019, p. 177) de que os estereótipos sobre afroamericanos presentes no imaginário da sociedade estadunidense nos séculos XIX e XX, que representavam homens negros como figuras caricatas interessadas apenas em beber e se divertir, foram formas de apagamento da importância do trabalho do indivíduo negro.

Como é fácil observar, muitos desses estereótipos percorreram os dois séculos passados e se manifestam fortes no presente, mas mais ambivalentes, atravessados por diferentes clivagens, frutos de mudanças históricas, sociais 
e culturais. Um outro aspecto que permanece forte nas manifestações contemporâneas do racismo é a participação das forças de segurança do Estado. Conforme apontado anteriormente, e seguindo o pensamento conceitual dos estudos de performance, os agentes detentores do monopólio da violência estatal têm papel fundamental no roteiro da violência racial, como é possível constatar no caso do assassinato de George Floyd. Mas esse papel também atravessa o imaginário social, sendo parte constitutiva das relações raciais nos Estados Unidos (e, nunca é demais lembrar, no Brasil). Um encontro no Central Park, em Nova York, no dia 25 de maio de 2020, horas antes do assassinato de George Floyd, ilustra de maneira singular como um imaginário social moldado pelo racismo e pela atuação discriminatória de parte da polícia se manifesta.

Christian Cooper, afroamericano de 57 anos, caminhava no Central Park, naquele 25 de maio, observando aves com seu binóculo. Amy Cooper, uma mulher branca, passeava com seu cachorro sem coleira, contra as recomendações indicadas naquele local. Christian abordou a mulher e pediu que amarrasse seu cachorro, ao mesmo tempo em que gravava Amy e seu animal, um ato comum para observadores de pássaros que se deparam com pessoas com cachorros soltos no parque. Amy, sentindo-se ofendida, ligou, quase como uma reação instintiva, para a polícia e afirmou que havia um homem negro filmando e fazendo ameaças a ela e a seu cachorro. A polícia não chegou a ir ao local e a gravação feita por Christian, postada em sua conta na rede social Facebook, viralizou como mais um encenação sórdida de um roteiro comum: uma pessoa branca, sentindo-se ameaçada pela simples presença de um indivíduo negro, contata a polícia.

Encarando a violência policial de cunho racial como um comportamento restaurado, é possível pensar a emergência de cada caso citado neste artigo em ligação umbilical não só com a atuação da força policial nos Estados Unidos, mas também com seus primórdios. O acadêmico Khalil Muhammad pontua, em entrevista para a revista eletrônica Vox ${ }^{5}$, que a noção de criminalidade surge ligada a rebeliões de escravizados, antes da abolição. Logo após o fim do regime escravocrata, quaisquer reivindicações por mais direitos ou participação social dos afroamericanos foi criminalizada e rechaçada, produzindo um ciclo vicioso no qual a população negra americana é ligada a altas taxas de criminalidades, que diminuem ainda mais sua integração 
a uma sociedade cuja parte considerável da população não aceitou o fim da escravidão. Denise Ferreira da Silva (2019, p. 178) nomeia esse processo - que permeia a trajetória pós-escravidão da população afroamericana e que mobiliza dispositivos econômicos, jurídicos e securitários — de acumulação negativa, responsável por manter, até o presente, parte considerável da população negra despossuída economicamente.

A cisão deixada nos Estados Unidos após a abolição da escravatura fez do racismo uma política pública em diversos estados por meio das leis segregacionistas Jim Crow ${ }^{6}$. Como aponta Muhammad em sua entrevista, muitos dos frequentes linchamentos de afroamericanos no sul do país tiveram participação de oficiais de polícia, seja diretamente, na violência contra a vítima, ou indiretamente, desarmando ou mesmo prendendo o indivíduo espancado. Muitas vezes, o cadáver da vítima negra era pendurado em galhos de árvores com uma grossa corda envolvendo seu pescoço ${ }^{7}$. Não foram raros os casos em que, nessas situações, investigações policiais concluíram que a vítima havia tirado sua própria vida ${ }^{8}$

Se, por um lado, pensar a violência policial e o racismo como um evento performático é indicar que seguem roteiros e constantemente reativam papéis e reatualizam acontecimentos passados, por outro lado, é urgente apontar para as respostas e as lutas contra o apagamento dos rostos e silenciamento das vozes negras, que emergem a cada vez que uma violência é cometida contra a população afroamericana. Afinal, como pontua Foucault (1999, p. 91), “lá onde há poder há resistência”. Tal resistência, de grande força performática, é também uma luta pelo futuro, afinal, este apenas é possível quando o trauma que atravessa o passado tenha sido transcendido (TAYLOR, 2009, p. 11).

6 As chamadas leis Jim Crow eram compostas por um conjunto imposições segregacionistas implementadas no sul dos Estados Unidos. Tais leis, impostas até 1965, visavam impedir o desenvolvimento econômico e social da população afroamericana, inclusive retirando os ganhos que essa população conquistou no chamado período de Reconstrução dos Estados Unidos, iniciado após o fim da guerra civil.

7 Após a guerra civil americana, linchamentos de homens e mesmo mulheres afroamericanas eram frequentes. Os assassinos costumavam pendurar os corpos em galhos de árvores com cordas no pescoço das vítimas, o que tinha uma dupla função: simular um suicídio, muitas vezes confirmado por médicos legistas, ainda que um exame médico básico facilmente afirmasse o linchamento; e intimidar a população negra.

8 Se o roteiro, tal qual destacado anteriormente, funciona por meio de reativações, o enforcamento de afroamericanos, e a negligência policial que aponta suas mortes como suicídios, cruza o tempo e assombra o presente. Uma matéria do periódico americano Washington Post destaca esse aspecto. Disponível em: <https://www.washingtonpost.com/outlook/2020/06/22/black-victims-hanging-suicide/>. Acesso em: 6 de abr. de 2021. 


\section{Lutas pelo olhar}

bell hooks (2019, p. 215) aponta que diferentes técnicas de subjugação de afroamericanos escravizados buscavam inibir sua capacidade de agência, especialmente por meio do controle de seu olhar, que nunca deveria ser direcionado a uma pessoa branca. Esse bloqueio da agência do sujeito negro a partir da administração do seu olhar é ainda presente de forma espraiada na sociedade contemporânea. Ao manter Floyd de bruços, com o pescoço sob seu joelho, Derek Chauvin impedia que o sujeito que matou o olhasse diretamente e fazia com que seus pedidos de socorro fossem apenas lamentos de um sujeito animalizado. Por outro lado, é justamente na possibilidade de olhar que há a potência de criação de espaços de agência para pessoas negras, nos quais se possa interrogar o olhar do outro e olhar para si, "dando nome" ao que se vê (HOOKS, 2019, p. 217).

Pensando com James Baldwin, a interdição da reciprocidade do olhar entre brancos e negros é também uma causa e uma consequência do racismo, uma vez que a cor negra funciona, argumenta Baldwin (1998, p. 722, tradução nossa), “como o espelho mais desagradável” para o sujeito branco. É possível, a partir daí, encarar o ativismo e a luta contra o racismo como uma disputa para olhar e pelo olhar. Ida B. Wells, jornalista investigativa e ativista pelos direitos civis, dedicou boa parte de sua vida à documentação dos linchamentos de afroamericanos no sul do Estados Unidos, batalhando para que os sujeitos mortos fossem olhados como vítimas da violência racial e seus assassinos brancos (que, com frequência, eram agentes da lei e proprietários de terra) fossem observados como tal. A ação desses ativistas mostra que o direito de aparecer não é universal, pois é constantemente minado por exercícios de poder que qualificam quem pode ou não se expor (BUTLER, 2019, p. 57). Sua luta, exemplificada na atuação de grupos como Black Lives Matter e Movement for Black Lives, "busca produzir uma fenda na esfera de aparecimento, expondo a contradição por meio da qual a sua reivindicação de universalidade é proposta e anulada" (ibidem, p. 57-58).

Sendo o roteiro performático um indicador de reativações de eventos, é interessante também pensar os protestos contra a violência racista como modos de comportamentos restaurados, acontecimentos reencenados nessa luta em torno do olhar. Antes de prosseguirmos, é pertinente seguir as pistas dadas por Leda Maria Martins sobre a característica de repetição da performance. Leda, partindo de Richard Schechner, afirma que um comportamento restaurado - ou seja, o evento performático - é "a dupla repetição de uma ação já repetida, repetição provisória, sempre sujeita 
à revisão, sempre passível de reinvenção; repetição que nunca se oferece da mesma maneira, mesmo quando sustentada pela constância da transmissão" (MARTINS, 2003, p. 66). ${ }^{9}$

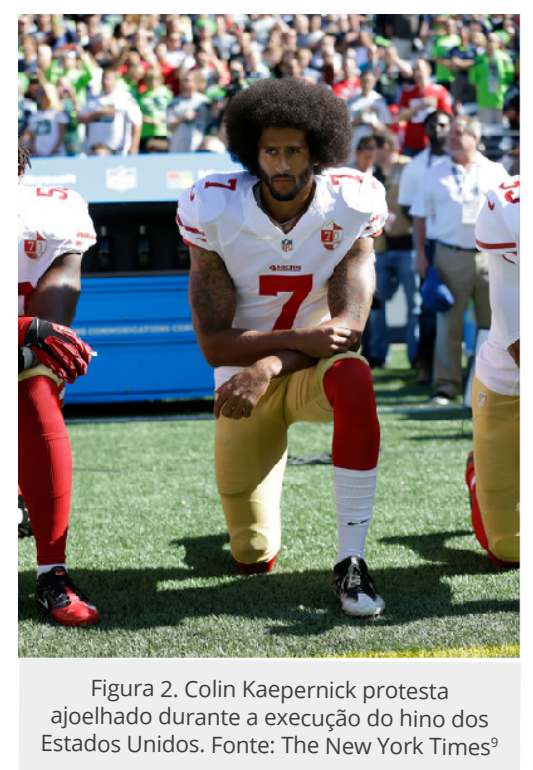

Sob essa ótica, o protesto de grande força performática — e midiática — do ex-jogador da NFL ${ }^{10}$ Colin Kaepernick pode ser encarado em suas filiações com outras manifestações contra a violência racial. Ao início de um jogo do final da pré-temporada da liga de futebol americano, Kaepernick, quarterback do time San Francisco 49ers, permaneceu sentado durante a execução do hino nacional dos Estados Unidos, um evento solene que, segundo definido no código de leis do país, deve ser acompanhado "em pé e com a mão direita sobre o coração". Em uma entrevista após o jogo, Kaepernick definiu seu ato como um protesto contra a violência policial dedicada a populações negras ${ }^{11}$. No jogo seguinte, o quarterback manteve-se ajoelhado e silencioso durante a execução do hino (fig. 2), seguindo o conselho de Nate Boyer, ex-jogador de futebol americano e ex-militar, para quem se ajoelhar é uma forma de

9 Disponível em: <https://www.nytimes.com/2020/06/05/sports/football/george-floyd-kaepernickkneeling-nfl-protests.html>. Acesso em: 6 de abr. de 2021.

10 National Football League, principal liga de futebol americano.

11 Há diferentes interpretações sobre significados do hino nacional dos Estados Unidos, The Starspangled Banner. Afirma-se com frequência que o hino homenageia forças militares e policiais mortas em serviço ou o país de forma mais ampla. Seja por acentuar um patriotismo com definições restritas de quais indivíduos são verdadeiros americanos ou por honrar forças de segurança que tểm sua parte na violência racial, protestos durante a execução do hino nacional atravessam a história dos Estados Unidos. 
protesto respeitosa que remete ao ato de orar e a homenagens prestadas por militares a companheiros mortos em serviço.

As respostas ao protestos foram amplas, desde acusações de desrespeito a veteranos de guerra ou exigências de demissão do jogador à solidariedade mostrada por outros atletas e membros da sociedade civil. Afinal, se pensarmos a execução do hino nacional como um evento solene, no qual o comportamento possível está inclusive codificado em lei (ficar de pé com a mão direita sobre o peito esquerdo), o ato de Kaepernick consistiu no deslocamento de um comportamento para um local onde ele seria inadequado ou inesperado, o que o enquadra como algo novo ou mesmo chocante (SCHECHNER, 2003, pp. 32-33). Durante a temporada de 2016-2017, vários jogadores de distintos times da NFL mantiveram-se ajoelhados durante a execução do hino e atletas de outras modalidades esportivas repetem o ato desde então em diferentes ocasiões. Ajoelhar-se tornou-se também um gesto recorrente em protestos nos Estados Unidos, especialmente os que se voltam contra o racismo. Diferentes veículos de comunicação, como Times, Washington Post ou Wall Street Journal, destacaram que, após o início dos protestos, emergiram com frequência nas redes sociais imagens que exibiam Martin Luther King Jr. (Fig. 3), principal ativista do movimento por direitos civis nos Estados Unidos, e vários manifestantes ajoelhados durante uma oração antes de serem presos por protestarem sem uma permissão pública em Selma, Alabama.

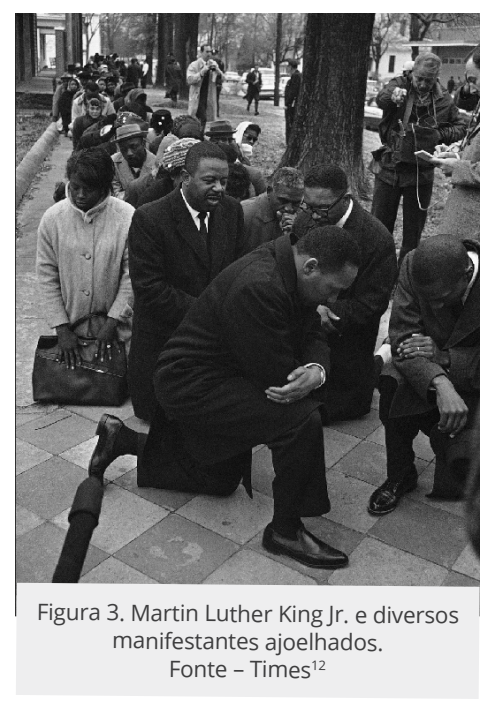

12 Disponível em: <https://time.com/4955717/trump-protests-mlk-martin-luther-king-kneeling/> Acesso em: 6 de abr. de 2021. 
Uma outra imagem, símbolo da luta abolicionista britânica e que representa um homem negro escravizado de joelhos (Fig. 4), também foi, mesmo que de forma indireta, associada aos protestos iniciados por Kaepernick. É pertinente observar nessas associações uma idealização do gesto de Kaepernick, uma vez que a manifestação inicialmente foi realizada com o jogador sentado durante o hino nacional e a decisão de se ajoelhar veio por conselho de Nate Boyer e como uma forma de se antecipar a acusações de desrespeito com a bandeira ou de antipatriotismo - queixas que, de todo modo, foram e continuam sendo feitas.

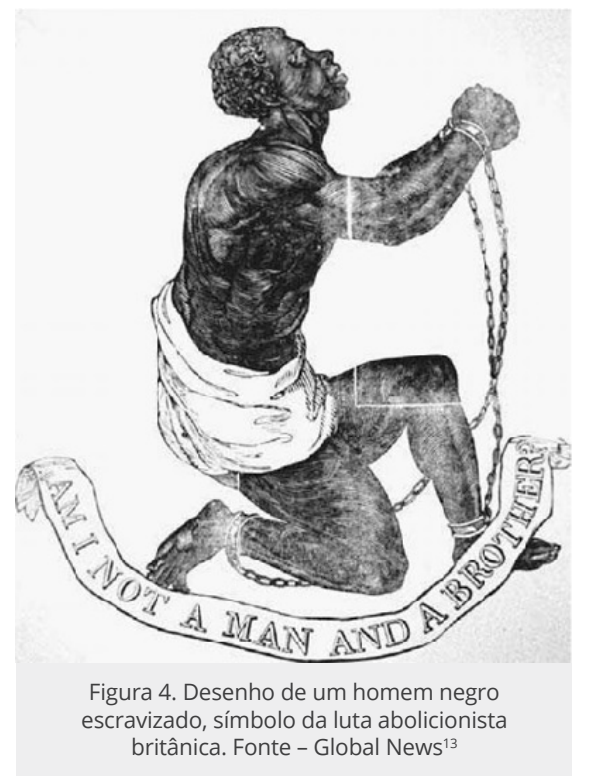

Por outro lado, se tomarmos o protesto de Colin Kaepernick como manifestação específica do roteiro mais amplo da luta contra a violência racial, ou seja, sob a forma de um comportamento restaurado, seu gesto, mesmo não havendo sido diretamente influenciado por Martin Luther King Jr., é como se fosse, construindo uma ligação orgânica com o gesto de se ajoelhar realizado 50 anos antes. O se ajoelhar é, nessa direção, o que permite que se estabeleça, entre as fotos do atleta e do ativista e a ilustração do escravizado, um nexo essencial para além das "simples relações de causalidade" entre as imagens (DIDI-HUBERMAN, 2018, p. 284). 
Pensando com Leda Maria Martins (2002, p. 85), poderíamos falar na emergência de um tempo espiralar no ato performático de Kaepernick, no qual o atleta se encontra com King Jr., não por meio de um ato que atravessa linearmente um período de mais de meio século, mas a partir da reativação e atualização de uma "ação, similar e diversa, já realizada tanto no antes quanto no depois do instante que a restitui, em evento" (MARTINS, 2002, p. 85), inclusive esvaziando a ideia de uma sucessividade temporal. Um gesto - de Colin - que faz emergir e ressignifica um outro, realizado décadas no passado - o de King Jr., - que, por sua vez, dá força e diferentes sentidos a um ato realizado no presente.

A vinculação entre as fotos de Kaepernick e King Jr. — que aqui reforçamos especialmente a partir do gesto que as atravessa - ressalta o ponto de Georges Didi-Huberman (2012, p. 216) de que uma imagem não é apenas um "corte praticado no mundo dos aspectos visíveis", mas uma impressão e um rastro do tempo que lhe é contemporâneo e também de "outros tempos suplementares". A força de cada registro da luta contra a violência racial é também a força de todas as outras imagens e temporalidades que emergem e se cruzam.

Ao mesmo tempo, não é possível ignorar certas contradições em torno do protesto, como a posterior atuação do próprio Colin como modelo em propagandas da marca esportiva Nike, que resultou em uma valorização de mercado da empresa, especialmente se observamos que o racismo é um fator estrutural da acumulação financeira e da formação de qualquer Estado capitalista (ALMEIDA, 2019, p. 111). Assim, diminuído o risco de romantizar o ato de Kaepernick, podemos pensar seu gesto, tantas vezes repetidos e por tantos indivíduos diferentes, como um esboço de resposta ao questionamento feito por Diana Taylor (2020, p. 4, tradução nossa) no contexto de protestos e manifestações políticas: “como vivemos e respondemos eticamente a esta brutalidade sistêmica, sabendo muito bem que muitos de nós estamos embutidos nela e nos beneficiamos das desigualdades econômicas que ela produz?".

Feitas essas observações, podemos focar no que, à primeira vista, é o fator mais pronunciado do protesto de Colin: seu gesto de se ajoelhar. Um gesto, como propõe Agamben (2018, p. 3), é carregado de uma tensão marcada por sua incessante repetição. O gesto é, ele mesmo, uma suspensão, que emerge entre dois movimentos ao mesmo tempo que é atravessada pela 
motilidade. É também suspensão da relação com vontades ou com fins, um meio que exibe a si mesmo, o que lhe dá uma inerente qualidade política, já que, por meio do gesto, "cada corpo, uma vez liberado de sua relação voluntária com um fim, seja orgânico ou social, pode, pela primeira vez, explorar, sondar e mostrar todas as possibilidades de que é capaz" (ibidem., p. 5), mesmo que na fugacidade de alguns segundos ou minutos. Ao se ajoelhar, Colin abriu uma lacuna no espetáculo consensual de um jogo de futebol, criando um "campo expressivo de possibilidades" (TAYLOR, 2020, p. 247, tradução nossa) sempre prestes a se desfazer, no qual o jogador lamenta as mortes de homens e mulheres afroamericanas e luta para mostrar que seus corpos, suas vidas, sempre possam muito mais ${ }^{14}$.

O gesto, podemos complementar, se destaca do estado de coisas cotidiano, como:

[...] um cruzamento entre a vida e a arte, o ato e a potência, o geral e o particular, o texto e a execução. Ele é um pedaço de vida subtraído do contexto da biografia individual e um pedaço de arte subtraído da neutralidade da estética: pura práxis. (AGAMBEM, 2015, p. 79).

Performances são, segundo argumenta Richard Schechner (2003, p. 34), comportamentos marcados, acentuados ou mesmo separados do simples viver. Nesse sentido, é possível destacar uma qualidade performática do gesto - ou mesmo uma qualidade gestual da performance - especialmente se notamos sua (potencial) repetição.

Kaepernick possivelmente antecipou poucas das reações ao seu gesto de protesto. Seu contrato com o time San Francisco 49ers foi encerrado na temporada seguinte à da partida em que pela primeira vez o jogador não se levantou com a mão sobre o peito durante a execução do hino e, desde então, Colin não foi contratado por outra equipe da principal liga de futebol americano. Em contrapartida, sua marca sobre os protestos subsequentes contra a violência racial, particularmente entre pessoas mais jovens, é indelével. Se as revoltas e os levantes tendem a depender de uma metáfora organizadora, materializada em "uma figura de alguém que se levanta" (BUTLER, 2016, p. 26, tradução nossa), mesmo permanecendo ajoelhada, populações pobres. Muitos indivíduos recebem bolsas em universidades pagas do país para que joguem por times das instituições na qual estudam, como no caso de George Floyd e Colin Kaepernick. Colin jogou futebol americano pela Universidade de Nevada, onde se formou em administração de empresas, enquanto Floyd frequentou universidades na Florida e no Texas jogando basquete, mas abandonou o ensino superior antes de sua graduação. 
Kaepernick é, para diversos jovens negros e brancos, essa figura e seu gesto de se ajoelhar é o símbolo mais destacado dos recentes protestos contra a violência policial racista catalisados pelo assassinato de George Floyd.

\section{8 minutos e 46 segundos}

O levante, mostra-nos Judith Butler (2016, p. 23), é um evento que busca pôr fim a uma condição sofrida já há tempo demais. Cada vez que um grupo de pessoas ou um povo se levanta, é porque seu sofrimento atingiu uma intensidade e uma duração para as quais não há resposta senão a revolta, a luta para que as coisas não sejam mais como são. O levante é expressão da sobrevivência do desejo em cada espaço concebido para neutralizá-lo (DIDI-HUBERMAN, 2016, p. 16). Quem se levanta em revolta o faz com uma certa força, "uma intenção corpórea e visceral" (BUTLER, 2016, p. 25, tradução nossa) que não é singular, mas partilhada, ou seja, alguém nunca se levanta sozinho, pois a revolta necessita do reconhecimento de que não apenas o sofrimento de um indivíduo é partilhado, mas que todo um conjunto de sujeitos está constantemente exposto a um sofrimento além de qualquer limite aceitável (ibidem, pp. 22-23).

Cada revolta contra a violência racial é a reativação do reconhecimento de que uma parte expressiva da população sofreu e continua sofrendo de forma dramática e a morte de um homem ou uma mulher negra é um martírio partilhado. Ao mesmo tempo, também é possível encarar parte desses protestos, que muitas vezes agregam pessoas das mais diversas etnias, como uma assembleia de corpos que rejeita a "precariedade induzida social e economicamente" (BUTLER, 2019, p. 31), em um exercício performativo "do direito de aparecer, uma demanda corporal por um conjunto de vidas mais vivíveis" (ibidem).

No dia seguinte à morte de George Floyd, as ruas de Minneapolis foram tomadas por milhares de manifestantes que, nas semanas seguintes, viraram milhões, espalhados por todos os Estados Unidos. A dimensão dos protestos e a violenta repressão de muitos deles possuem correspondência apenas com os movimentos pelos direitos civis na década de 1960 e a coragem de cada manifestante pode ser comparada à daqueles que foram às ruas mais de 50 anos atrás, pois o risco não vinha apenas da possível repressão violenta das forças policiais, mas de uma pandemia causada pela proliferação do novo coronavírus, que, no dia seguinte ao primeiro protesto, alcançou 
a tétrica marca de 100 mil vítimas americanas. Contra a repetição do grito "eu não posso respirar", a respiração compartilhada, conspiração, de um sem número de pessoas.

Entre marchas pacíficas, palavras de ordem, departamentos policiais incendiados e bombas de gás lançadas por forças de segurança, um momento era o ápice de várias dessas manifestações: dezenas ou mesmo centenas de manifestantes se ajoelhavam por cerca de 8 minutos e 46 segundos ${ }^{15}$ (fig. 5). Por ser um evento marcado no "simples viver", o comportamento restaurado, Schechner (2003, p. 34) aponta, pode ser aprimorado, guardado e resgatado. O gesto de Kaepernick era, a cada vez, reencenado, mas recontextualizado e ressignificado.

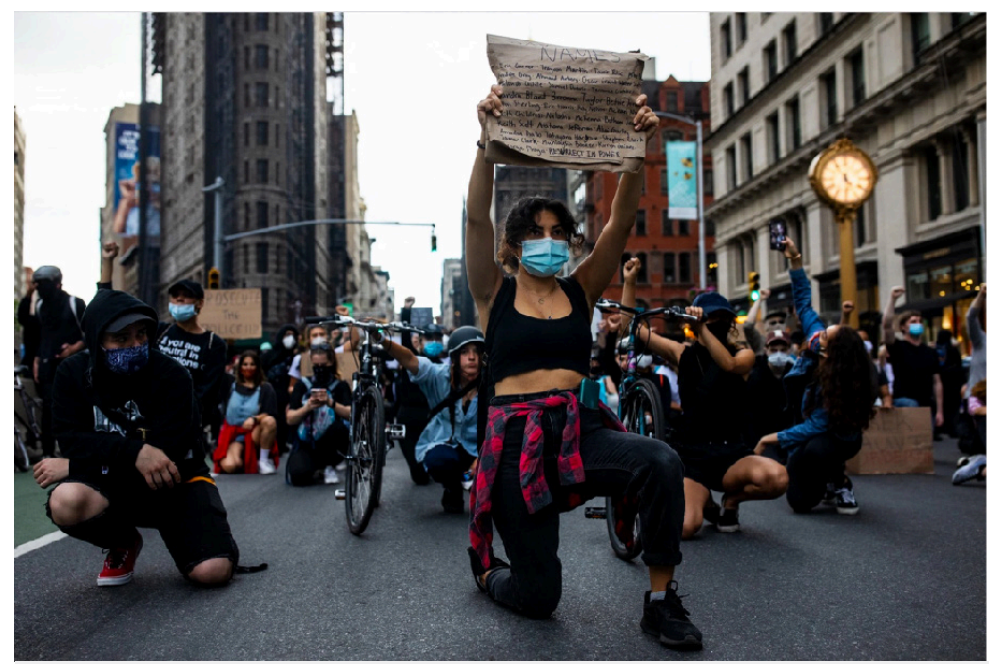

Figura 5. Manifestantes ajoelhados durante um protesto contra a violência policial em Nova York. Fonte: The New York Times ${ }^{16}$

A performance é, simultaneamente, um ato de exposição e um processo de subjetivação, nota André Brasil (2011, p. 4). O evento performático é o momento no qual "um corpo se expõe e ao se expor cria a situação na qual se expõe, não sem, no mesmo gesto, criar-se a si mesmo. Uma forma

15 Nas apurações iniciais das causas da morte de George Floyd, os investigadores apontaram, com base na denúncia do procurador de Hennepin County, que Chauvin se ajoelhou por oito minutos e quarenta e seis segundos sobre o pescoço de Floyd. Pouco tempo depois, afirmaram que a duração do enforcamento foi quase um minuto maior. Ainda assim, oito minutos e quarenta e seis segundos virou um símbolo da violência policial e marcou a duração de momentos de silêncio ou gestos de ajoelhar em homenagem a Floyd.

16 Disponível em: <https://www.nytimes.com/2020/06/05/sports/football/george-floyd-kaepernickkneeling-nfl-protests.html>. Acesso em: 6 de abr. de 2021. 
aparece e ganha forma - não previamente - mas à medida em que aparece" (BRASIL, 2011, p. 5). Pensar o protesto como espaço performático permite seu enquadramento de modo singular: torna-se uma área de atuação, um espaço onde quem se levanta pode aparecer de forma diferente (TAYLOR, 2020, p. 61). O gesto de se ajoelhar em cada manifestação é o momento decisivo desse tornar-se outro, do corpo que se expõe e se (re)cria, do imaginar e construir um outro mundo possível.

Faz-se necessário notar a ambivalência da aparição do gesto de se ajoelhar, se o analisamos nas manifestações catalisadas pela morte de George Floyd. O gesto não deixa de guardar uma referência à forma como Chauvin sufocou Floyd, esmagando seu pescoço com o joelho. Porém, feito por manifestantes que lutam justamente pelo fim da repetição do roteiro fúnebre da violência policial, a brutalidade associada ao ato é tornada inoperante ${ }^{17}$.

Se a assembleia é um local de aparecimento que existe apenas no "entre" os corpos de cada manifestante (BUTLER, 2019, p. 82), esse espaço corre, a cada momento, o risco de dispersar-se, anseio maior de uma ordem policial que almeja apenas a continuidade de formas atuais de domínio e hegemonia, manifestadas em cada bala de borracha e em cada desejo de criminalização dos protestos. Nisto, não podemos esquecer que todo levante chega ao fim e o fracasso faz parte de sua própria definição (BUTLER, 2016, p. 31). Se não fosse assim, não seria um levante, mas uma revolução. Os que se exaltam com os levantes "vêem-se muitas vezes deixados com uma terrível desilusão e sensação de perda" (ibidem, p. 36, tradução nossa) com a dissolução da assembleia de pessoas em revolta ou com o assassinato de mais um homem ou mulher negra. Mas um levante chama o próximo, fermentado pela revolta contra a repetição do roteiro macabro da violência racial e pela lembrança de um gesto incansavelmente repetido, o se ajoelhar, que é também se levantar e lutar, abertura efêmera de um espaço político que permite vislumbrar no horizonte outras formas de vida e maneiras de estar junto.

Os vislumbres de um outro horizonte político e sensível sobrevivem nas imagens desses levantes, que correram e ainda correm o mundo, e permeiam perfis em redes sociais de sujeitos que, por semanas ou mesmo

17 Vários policiais ao redor dos Estados Unidos se ajoelharam em solidariedade aos manifestantes, em um ato ambíguo. Por um lado, podia-se pensar que muitos oficiais despertavam para sua responsabilidade na violência racial, ao mesmo tempo que seu gesto remetia à violência cometida por Chauvin, ainda mais se considerarmos que desde o homicídio de George Floyd, ao menos dois assassinatos de afroamericanos por forças policiais foram cometidos. Rayshard Brooks, de 27 anos, foi morto em Atlanta, Georgia, com dois tiros pelas costas, e Daniel Prude, homem de 41 anos com histórico de problemas mentais, morreu asfixiado após ser contido pela polícia durante um surto. 
meses, fizeram da luta antirracista o motor de suas vidas. Ainda que perdidas na banalidade da miríade de fotos enviadas diariamente ao Instagram ou Facebook, são imagens que ardem (DIDI-HUBERMAN, 2012, p. 216). Ardem não apenas pela violência e pela dor que causaram os levantes dos quais são registro, mas pelo desejo que as anima; ardem, especialmente, pela memória que ativam e que constróem (ibidem). Que tal memória possa, sempre que necessário, ser invocada lado a lado com a de Martin Luther King Jr. e Colin Kaepernick, estejam ajoelhados ou firmes em seus pés, e sirva de modelo para todos aqueles que lutarão no futuro.

\section{Considerações finais}

No caminho percorrido neste ensaio, seguimos a proposição de abordar a violência policial de caráter racial nos Estados Unidos, que possui infelizes correspondências em diversas partes do globo, e diferentes manifestações antirracistas que a partir daí se insurgem nos amparando nos estudos de performance, ou seja, encarando tais eventos como comportamentos restaurados que, no momento mesmo de sua expressão, retomam acontecimentos prévios. Confrontar tais eventos por intermédio dessa lente metodológica permite ver seus registros imagéticos com um olhar que vai além dos aspectos formais, uma mirada que busca relações de proximidade, pensando as reativações, as repetições, as reencenações. Confrontados a partir do gesto de se ajoelhar, esses registros retomam toda uma linhagem de lutas pela igualdade racial ao mesmo tempo que dialogam diretamente com outras tantas imagens que povoam nosso imaginário e a esfera midiática, seja no noticiário, em partidas das mais diferentes modalidades esportivas ou até mesmo em concertos musicais.

Tais ligações são formas de sobrevivência dos gestos e dos corpos que aparecem nessas imagens, pequenas vitórias, diante do fracasso virtual de todo levante, dos sujeitos que, em sua gestualidade, se mostram no meio de seu aparecer (AGAMBEN, 2018, p. 4), criando-se a partir dessa exposição. Afinal, após um levante, já não se é o mesmo, nem o mundo é mais como era.

Reno Beserra Almeida é doutorando no Programa de Pós-Graduação em Comunicação da Universidade Federal de Pernambuco. É mestre pelo Programa de Pós-Graduação em Artes da Universidade Federal do Ceará (UFC).

reno.almeida@ufpe.br 


\section{Referências}

AGAMBEN, G. Meios sem fim: notas sobre a política. Belo Horizonte: Autêntica Editora, 2015.

Por uma ontologia e uma política do gesto. In: Cadernos de leitura, n. 76. Belo Horizonte: Edições Chão da Feira, 2018. Disponível em: <https://chaodafeira.com/wp-content/uploads/2018/04/cad76ok.pdf>. Acesso em 20/2/2021.

ALMEIDA, S. Racismo estrutural. São Paulo: Pólen, 2019.

BALDWIN, J. Collected essays. Nova York: Literary Classics of the United States, 1998.

BRASIL, A. A performance: entre o vivido e o imaginado. In: Anais do XX Encontro da Compós. Porto Alegre: UFRGS, 2011. Acesso em: 30 de ago. de 2020.

BUTLER, J. Corpos em aliança e a política das ruas: notas para uma teoria performativa de assembleia. Rio de Janeiro: Civilização Brasileira, 2019.

. Uprising. In: DIDI-HUBERMAN, Georges (org.), Uprisings. Paris: Gallimard, Jeu de Paume, 2016.

DIDI-HUBERMAN, G. Uprising. In: DIDI-HUBERMAN, Georges (org.), Uprisings. Paris: Gallimard, Jeu de Paume, 2016.

. Quando as imagens tocam o real. In: Pós, Belo Horizonte, v. 2, n. 4, pp. 204-219, 2012. Acesso em: 28 de jul. de 2021.

FERREIRA da SILVA, D. A dívida impagável. São Paulo, 2019.

FOUCAULT, M. A história da sexualidade I: a vontade de saber. Rio de Janeiro: Edições Graal, 1999.

Microfísica do poder. Rio de Janeiro: Edições Graal, 1979.

HOOKS, b. Olhares negros: raça e representação. São Paulo: Editora Elefante, 2019.

KILOMBA, G. Memórias da plantação: episódios de Racismo Cotidiano. Rio de Janeiro: Cobogó, 2019.

MARTINS, L. M. Performances da oralitura: corpo, lugar da memória. In: Letras, Santa Maria, n. 26, pp. 63-81, 2003. Acesso em: Acesso em: 24 de out. de 2020.

. Performances do tempo espiralar. In: Performances, exílio, fronteiras: errâncias territoriais e textuais. Belo Horizonte: Departamento de Letras Românicas, Faculdade de Letras/UFMG, 2002.

MBEMBE, A. Crítica da razão negra. São Paulo: n-1 edições, 2018.

SCHECHNER, R. "O que é performance?" In: O percevejo - Revista de teatro, crítica e 
estética, Rio de Janeiro, v. 12, p. 25-50, 2003. Acesso em: 24 de set. de 2020.

TAYLOR, D. ¡Presente!: the politics of presence. Durham: Duke University Press, 2020.

O arquivo e o repertório: performance e memória cultural na América Latina. Belo Horizonte: Ed. UFMG, 2013.

O trauma como performance de longa duração. In: O Percevejo Online, Rio de Janeiro, v. 1, n. 1, p. 2-12, 2009. Acesso em: 28 de set. de 2020.

Artigo recebido em 06/04/2021 e aprovado em 17/08/2021. 